\title{
Economic, Social and Environmental Aspects of the Impact of the Universiade - 2013 on Development of Kazan City and Tatarstan Republic
}

\author{
Bagautdinova N. G. ${ }^{1}$, Mingazova N. M. ${ }^{1}$, Zamaletdinov R. I. ${ }^{1}$, Panasyuk M. V. ${ }^{1}$, Safiullin L. N. ${ }^{1}$, Gafurov I. R. ${ }^{1}$, \\ Glebova I. S. ${ }^{1}$, Zotova F. R. ${ }^{2}$, Kadyrov A. R. ${ }^{3} \&$ Suslova O. B. ${ }^{3}$ \\ ${ }^{1}$ Kazan Federal University, Institute of Management, Economics and Finance, Kazan, Russia \\ ${ }^{2}$ Volga State Academy of Physical Culture, Sports and Tourism, Russia \\ ${ }^{3}$ Board of the XXVII World Summer Universiade in Kazan, Russia \\ Correspondence: Bagautdinova N. G., Kazan Federal University, Institute of Management, Economics and \\ Finance, Kazan, 420008, Russia.
}

Received: December 27, 2014 Accepted: February 19, 2015 Online Published: April 30, 2015

doi:10.5539/ass.v11n11p115 URL: http://dx.doi.org/10.5539/ass.v11n11p115

\begin{abstract}
The article describes the methodological approaches used to study the influence of major international sporting events on the development of the city and region (on example of XXVII World Summer Universiade which held in the Russian Federation in the city of Kazan in 2013). This paper presents the results of economic, social and environmental consequences for the development of the city of Kazan and Tatarstan. Assessment of impacts is given in an integrated form, with the conclusions of the contradictory effects for the different areas of the city and the region.
\end{abstract}

Keywords: international competitions, XXVII World Summer Universiade, economic aspects, social aspects, Environmental impact assessment, Kazan city, Republic of Tatarstan

\section{Introduction}

World Summer and Winter Universiade, promoting international cooperation, peace and understanding between peoples is also a powerful incentive for the development of social and economic systems of city and region where it conducted as well as the modernization of all aspects of life (Malfas, Theodoraki, \& Houlihan, 2004; Mingazova et al., 2013). Consequences of major sporting events, including the Olympics, World Championships and Universiade, usually so tangible for the population of the region that specifically examined, including quantification of the dynamics of socio-economic indicators as well as evaluating changes in the quality parameters of regional society and environmental change.

Difficult and controversial nature of the interaction of major subsystems often leads to the fact that the positive effect on the development of one functional system causes negative changes in other systems. Among the identified positive effects material results were found (new and upgrade sports facilities, new transport infrastructure, the growth performance of the economy, etc.) as well as intangible heritage (increasing the attractiveness of a healthy lifestyle and sports, the growth of patriotism, etc.). Among the negative consequences there is the need to repay loans for the construction, environmental degradation, incomplete utilization of sports facilities after carrying out of games et al., which, in general, typical for most cities, where there has been a major international sporting events (Mingazova et al., 2013).

Existing and emerging evaluation approaches and methods enable to identify ways to maximize the positive socio-economic impact of each stage of the business cycle of the Universiade, and also allows generalize and use this experience in the future.

XXVII World Summer Universiade, held in Kazan from 6 to 17 July 2013, led to a fundamental transformation of the urban environment and changed the nature of socio-economic development of the city, leading to a significant impact on the dynamics of not only the region of the Republic of Tatarstan (RT) but Russia as a whole. Student project in its scope and complexity can be compared with the implementation of major industrial 
projects, which were implemented region in the XX - XXI centuries., including the construction of factories JSC "KAMAZ" in Naberezhnye Chelny, the company of "Nizhnekamskneftekhim" etc.

Currently, it became obvious that adequate results analyzing the effect of major sporting events on the region's development cannot be based only on the study of economic dynamics. They should cover all aspects of the existence and development of urban and regional societies in terms of their basic functional systems that are social, economic and environmental (2010). Therefore, the theoretical basis to conduct research on the effect of the 2013 Universiade on the development of the region and Kazan was the concept of sustainable development, the main findings of which (Ely, Smith, Stirling, Leach, \& Scoones, 2013) allow us to find solutions to the problems of economic growth and economic efficiency without harm to the environment and social development. The parameters of the dynamics of sustainable development led to the composition of indicators to assess the impact of the Universiade, which included the blocks corresponding to the three functional systems, determines the stability of the city and the region. These blocks are the ecological, economic and socio-cultural.

\section{Methodological Approaches and Research Materials}

Studies were conducted in 2012-2014. under the contract between Kazan (Volga) Federal University and ANO "Executive Board of the Universiade" by the Institute of Management and Territorial Development of KFU and Volga Region Academy of Physical Culture. To conduct research the time periods of the study were selected, the system of indicators that form the final assessment of changes identified, their theoretical and statistical significance was assessed. Evaluation was carried out for the level of influence of the city (Kazan) and region (Republic of Tatarstan).

According to this, studies to assess the impact of the Universiade included reviews of the state of the city and the region in three periods: 1) the beginning - 2009, completion - 2012; 2) the beginning - 30 days before the date of commencement of the World Universiade completion - 30 days after the closing date of the World Universiade on the official closing ceremony; 3) 30 days after the close - up of the 1st quarter 2014.

Approaches to complex estimation the impact have been developed, as well as methods of assessing the dynamics of each indicator. The initial state of the system relating to 2009 for each indicator estimates the value of 1 (equal to $100 \%$ ). Dynamics of changes was evaluated in accordance with the proportions change indicator values in fractions of 1 or as a percentage (Table 1). 57 evaluation indicators were selected as the main, including 28 economic, 19 social and 10 environmental (Mingazova et al., 2013).

Table 1. Methods of formation of evaluation indicators

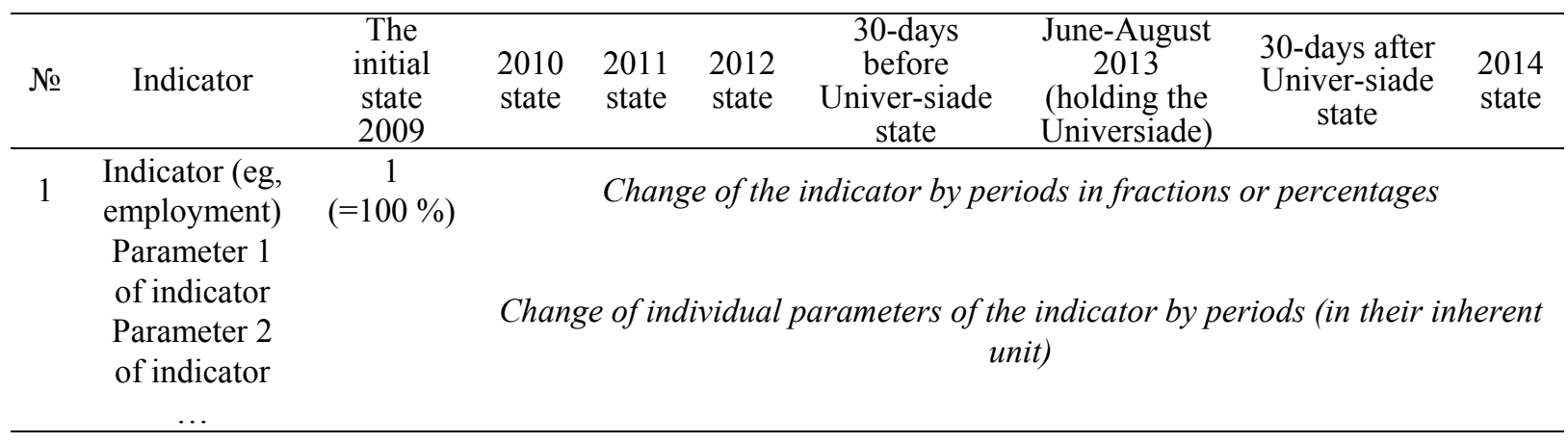

Material for the study were the data of statistical reports of the ministries of the Republic of Tatarstan for the period 2009-2014 (Ministry of Economy, Ministry of Labour, Employment and Social Development, the Ministry of Industry and Trade Development, the Ministry of Ecology and Natural Resources, et al.), stock materials of Directorate of the Universiade, data from surveys and questionnaires, the results of environmental studies and measurements for the period 2009-2014. In ecological studies, methods of assessment of the environmental impact have been used (Mudarisov \& Mingazova, 2011).

The authors render deep gratitude to all the staff of KFU and Volga Region State Academy of Physical Culture, Sport and Tourism, participated in conduction of economic, social and environmental studies on this topic.

\section{Assessment of the Impact on Economic Performance}

According to the calculations of the dynamics of economic indicators number of general positive effects of the Universiade for the economic development of Kazan and the Republic was identified. Thus, in the period of 
preparation and holding of the Universiade steady growth of the indicator of employment was observed (Table. 2), which reached a peak in 2012 (1.8) and decreased slightly in early 2014, reaching, however, the value of 1,3 (30\% growth).

During the observation period there was a trend of stable growth of motorization of the city (1.27 times). The public transport system in the considered time interval has undergone significant changes. Traffic volumes have increased most rapidly in the period before the Universiade. The growth trend was completed by the beginning of 2013, after which traffic volumes have stabilized. There was a change in the ratio of shares of public transport, bus transport is dominated due to increase the share of the underground.

During the period under consideration steady growth in both nominal and real wages in the region observed. Showed a trend to some slowing down of rate of growth during 2012 and the first half of 2013. In general, the official average salary in Kazan higher than in the region. The essential point is the fact that growth in both nominal and real wages in Tatarstan higher than the average for the Russian Federation. Among the regions of the Russian Federation Tatarstan in this period is a leader in size and rate of growth of wages.

Table 2. Indicators of the impact of of the Universiade 2013 on the development of Kazan and Tatarstan Republic (2009-2014 gg.)

\begin{tabular}{|c|c|c|c|c|c|c|c|c|c|c|}
\hline & Indicator & 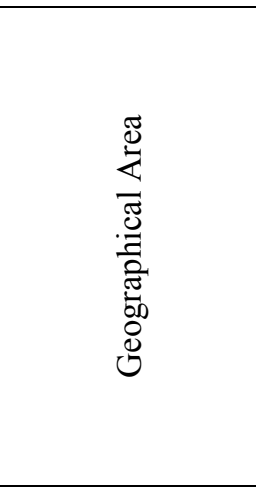 & 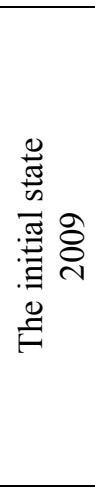 & $\begin{array}{l}\text { 菍 } \\
\text { in } \\
0 \\
\stackrel{0}{0}\end{array}$ & 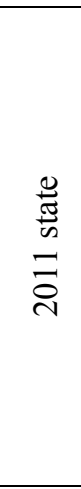 & 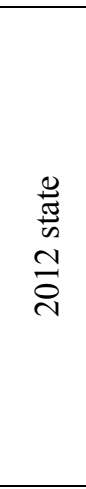 & 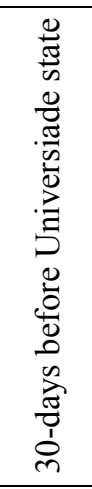 & 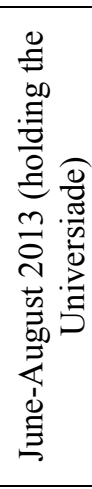 & 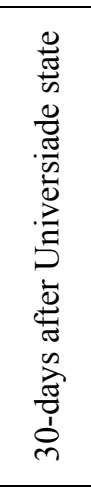 & 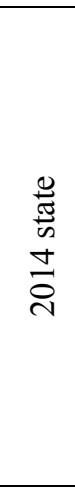 \\
\hline & Economic Block & & & & & & & & & \\
\hline 1 & Employment & Kazan & 1 & 1,8 & 1,8 & 1,8 & 1,7 & 1,7 & 1,3 & 1,3 \\
\hline 2 & Car park & Kazan & 1 & 1,01 & 1,1 & 1,2 & 1,25 & 1,26 & 1,26 & 1,27 \\
\hline 3 & Public transport & Kazan & 1 & 1,2 & 1,1 & 1,05 & 1 & 1 & 1 & 1 \\
\hline 4 & Hotel facilities & Kazan & 1 & 1 & 1 & 1,5 & 1,6 & 1,6 & 1,6 & 1,7 \\
\hline 5 & Hotel occupancy & Kazan & 1 & 1 & 1 & 1,16 & 1,36 & 2,09 & 1,93 & 1 \\
\hline 6 & Airport workload & Kazan & 1 & 1,31 & 1,77 & 2,11 & 2,59 & 2,17 & 2,52 & 1,7 \\
\hline 7 & International events & Kazan & - & & & 1 & 26,08 & 34,78 & 17,39 & 0 \\
\hline 8 & Wages & Kazan, Tatarstan & 1 & 1,2 & 1,3 & 1,5 & 1 & 1,05 & 1 & 1 \\
\hline 9 & Price indexes & Kazan, Tatarstan & 1 & 1,8 & 1,5 & 1,6 & 1 & 1,1 & 1,2 & 1 \\
\hline 10 & Price indexes in hotels & Kazan & 1 & 1 & 1 & 1,05 & 1,06 & 2,33 & 1,07 & 1 \\
\hline 11 & Real estate market & Kazan, Tatarstan & 1 & 1,08 & 1,24 & 1,55 & 1,51 & 1,54 & 1,53 & 1,55 \\
\hline 12 & The structure of budget revenues & Kazan, Tatarstan & 1 & 1,3 & 1,5 & 1,5 & 1,5 & 1,5 & 1,5 & 1,3 \\
\hline 13 & $\begin{array}{l}\text { Jobs created due to activities of the } \\
\text { Universiade }\end{array}$ & Kazan & 1 & 1,04 & 1,1 & 1,33 & 1,33 & 1,42 & 1,42 & 0 \\
\hline 14 & $\begin{array}{c}\text { New types of business related to the } \\
\text { Universiade }\end{array}$ & Kazan, Tatarstan & 1 & 1 & 1 & 1 & 1 & 1 & 1 & 1 \\
\hline 15 & $\begin{array}{c}\text { General paid wages (Universiade } \\
\text { events) }\end{array}$ & Kazan & 1 & 1,2 & 1,2 & 1,2 & 1,03 & 1,03 & 1,03 & \\
\hline 16 & $\begin{array}{c}\text { The effect of the catalyst from the } \\
\text { Games }\end{array}$ & Kazan & & & & & 1 & 1 & 1 & \\
\hline 17 & $\begin{array}{l}\text { Employment opportunities of people } \\
\text { with disabilities }\end{array}$ & Kazan & 1 & 1 & 1 & 1 & 1 & 1 & 1 & 1 \\
\hline 18 & Housing & Kazan & 1 & 1,07 & 1,30 & 1,38 & 1,42 & 1,41 & 1,44 & 1,44 \\
\hline 19 & Capacity of the Universiade venues & Kazan & 1 & 1 & 1 & 1,46 & 1,95 & 1,95 & 1,95 & 1,95 \\
\hline 20 & $\begin{array}{c}\text { Operation and Maintenance of the } \\
\text { Universiade }\end{array}$ & Kazan & & & 1 & 0,6 & 0,8 & 3 & 0,2 & \\
\hline
\end{tabular}




\begin{tabular}{|c|c|c|c|c|c|c|c|c|c|c|}
\hline 21 & $\begin{array}{c}\text { Transport infrastructure due to the } \\
\text { Universiade }\end{array}$ & Kazan & 1 & 1,19 & 1,36 & 1,51 & 1,54 & 1,52 & 1,42 & \\
\hline \multirow[t]{2}{*}{22} & $\begin{array}{c}\text { Impact of the transport system of the } \\
\text { Universiade }\end{array}$ & Kazan & 1 & 1 & 1 & 1,62 & 0,67 & 0,78 & 0,77 & \\
\hline & Social Block & & & & & & & & & \\
\hline 1 & Community centers and associations & Kazan, Tatarstan & 1 & 0,97 & 0,94 & 0,93 & 0,95 & 0,97 & 0,97 & 0,97 \\
\hline 2 & Sport and physical activity & Kazan, Tatarstan & 1 & 1 & 1,04 & 1,12 & 1,14 & 1,14 & 1,14 & 1,42 \\
\hline 3 & Sport activities among students & Kazan, Tatarstan & 1 & 1 & 1 & 1,1 & 1,07 & 1,25 & 1,45 & 1,74 \\
\hline 4 & Available sports facilities & Kazan, Tatarstan & 1 & 1 & 1 & 1,17 & 1,18 & 1,19 & 1,19 & 1,2 \\
\hline 5 & $\begin{array}{l}\text { The results on the Universiade, } \\
\text { Olympic Games, Paralympic Games } \\
\text { and World Championships }\end{array}$ & Kazan, Tatarstan & 1 & 1 & 0,69 & 0,51 & - & 1,25 & - & 3,67 \\
\hline 6 & National Doping Control & Kazan, Tatarstan & & & 1 & 1,5 & 2,0 & 2,0 & 2,0 & 2,0 \\
\hline 7 & Media, specializing in sports & Kazan, Tatarstan & 1 & 1 & 1 & 3,5 & 7,76 & 15,42 & 2,16 & 1,5 \\
\hline 8 & Sports broadcasting & Kazan, Tatarstan & 1 & 1 & 1 & 3,5 & 7,76 & 15,42 & 2,16 & 0 \\
\hline 9 & Media news & Tatarstan, Russia & 1 & 0,4 & 0,8 & 1,3 & 1,5 & 1,9 & 1,9 & 1,9 \\
\hline 10 & $\begin{array}{l}\text { Information and communication } \\
\text { technologies }\end{array}$ & Kazan, Tatarstan & 1 & 1,2 & 1,1 & 1,1 & 1,2 & 1,2 & 1,2 & 1,2 \\
\hline 11 & $\begin{array}{l}\text { Public opinion polls } \\
\text { Educational activities at the XXVII }\end{array}$ & Kazan, Tatarstan & - & - & - & - & - & - & - & - \\
\hline 12 & $\begin{array}{l}\text { World Summer Universiade } 2013 \text { in } \\
\text { Kazan }\end{array}$ & Kazan, Tatarstan & 1 & 1 & 1 & 1,3 & 1,9 & 1,4 & 1 & 1 \\
\hline 13 & Culture program & Kazan, Tatarstan & 0 & 1 & 3 & 3,8 & 1 & 4,2 & 0 & 0 \\
\hline 14 & $\begin{array}{c}\text { Recognition of emblem and the mascot } \\
\text { of Universiade }\end{array}$ & Kazan, Tatarstan & - & - & - & 1 & 1 & 0,82 & 1,01 & - \\
\hline 15 & The development of national sports & Tatars & 1 & 2,34 & 2,36 & 1,17 & 0,8 & 1,60 & 0,8 & 0,92 \\
\hline 16 & Volunteers & Kazan, Tatarstan & - & - & - & - & 1,0 & 1,0 & 0,9 & 0,25 \\
\hline 17 & The audience & Kazan & 0 & 0 & 0 & 0 & 0 & 0,95 & 0 & 0 \\
\hline 18 & Participants of the Universiade & Kazan, Tatarstan & 0 & 0 & 0 & 0 & 0 & 1 & 0 & 0 \\
\hline 19 & $\begin{array}{l}\text { Sustainable accessibility of the } \\
\text { Universiade venues } \\
\text { Environmental Block }\end{array}$ & Kazan, Tatarstan & 0 & 0 & 0 & 1 & 0 & 0 & 1 & 1 \\
\hline 1 & The quality of water & $\begin{array}{l}\text { Middle Volga } \\
\text { Region, Kazan }\end{array}$ & 1 & 0,7 & 0,8 & 0,7 & 0,90 & 0,8 & 0,8 & 0,8 \\
\hline 2 & $\begin{array}{l}\text { Air quality and emissions of gases that } \\
\text { cause the greenhouse effect }\end{array}$ & Kazan, Tatarstan & 1 & 1,1 & 1,1 & 1,16 & 1,09 & - & - & 1 \\
\hline 3 & Sewage treatment & Kazan, Tatarstan & 1 & 0,99 & 0,99 & 0,99 & 0,73 & - & - & - \\
\hline 4 & $\begin{array}{l}\text { The new treatment plant and waste } \\
\text { water treatment plants }\end{array}$ & Kazan, Tatarstan & 1 & 1 & 1 & 1 & 1 & 1 & 1 & 1 \\
\hline 5 & $\begin{array}{c}\text { Green areas and the extent of } \\
\text { landscaping }\end{array}$ & Kazan & 1 & 0,8 & 0,8 & 1,3 & 1,4 & 1,4 & 1,4 & 2,3 \\
\hline 6 & $\begin{array}{l}\text { Assessment of green plantations of the } \\
\text { city }\end{array}$ & Kazan & 1 & 0,8 & 0,7 & 0,8 & 1,2 & 1,2 & 1,2 & 1,2 \\
\hline 7 & $\begin{array}{c}\text { Assessment of the ecological status of } \\
\text { water bodies (lakes, reservoirs, small } \\
\text { rivers, artificial reservoirs) }\end{array}$ & $\begin{array}{l}\text { Middle Volga } \\
\text { Region, Kazan }\end{array}$ & 1 & 0,95 & 1 & 0,98 & 0,98 & 0,9 & 0,89 & - \\
\hline 8 & Assessment of Protected Areas & Kazan & 1 & 0,9 & 0,9 & 0,7 & 0,9 & 0,9 & 0,9 & 0,9 \\
\hline 9 & $\begin{array}{l}\text { Biological diversity and valuable } \\
\text { natural areas }\end{array}$ & Kazan, Tatarstan & 1 & 0,93 & 0,9 & 0,87 & 0,81 & 0,81 & 0,81 & 0,81 \\
\hline
\end{tabular}

For the period 2009-2012 the improvement of infrastructure of the hotel complex was observed that was motivated by the need to accommodate guests of the Universiade. The highest growth rates were typical for period of the Universiade, but they are preserved even after it. The occupancy rate of hotels in Kazan has grown over the period approximately in 2 times. This is due to the positive influence of the Universiade in 2013 from 
the standpoint of a tourist attraction. However, by the beginning of 2014 hotel occupancy has returned to the 2009 level.

Noticeable in comparison with 2009 (in 2,6 times 30 days before the Universiade and in 2.17 times in the period of its implementation) increase the number of regular and charter flights at the international airport "Kazan" is typical in the observed period. A similar trend was observed in the transit passenger traffic. 2009-2013 has seen steady growth in traffic volumes and 30 days after the Universiade observed decline, which by the beginning of 2014 goes to the level of 2011.

In 2012-2013 was a significant (35-fold) increase in the total number of interventions that have international status, but their number in the period after the Universiade decreased in comparison with the period of 30 days prior to its implementation.

In the analyzed period the growth rate of the price index was observed that until 2012 was not due to factor in the Universiade. During carrying out decline in growth the index from 1.6 in 2012 to 1.2 in the period of 30 days after the Universiade occurred. In the period 2009-2013 there was an increase in prices for hotel rooms (Table 2), an average of 2 times. The highest level $(2.33$-fold) was observed during the Universiade, after 30 days (1.07-fold).

During the period under study price growth in the real estate market in Kazan was marked (1.54-fold in 2013 in comparison with 2009). This may be due to the overall growth of real estate prices and rising real estate market during the period of preparation and holding Universiade 2013. However, significant fluctuations in real estate prices have not been fixed. Rising prices remained after the Universiade and comes in 2014 at the same rate as in 2013.

During preparation for the Universiade budget revenues of municipalities of Kazan and Tatarstan increased by 77 and $51 \%$, respectively. Moreover, the revenues of municipalities of Kazan grew faster than revenues of the regional budget. On the revenue side of municipalities of Kazan there was an increase both tax and non-tax revenues, as well as gratuitous receipts. But the growth rate of gratuitous receipts were considerably higher (an increase of more than twice). Growth of of budget revenues of the Republic of Tatarstan was provided by the tax and non-tax revenues. Growth of gratuitous revenue of the republic was negligible. In the period after the Universiade revenue budget of the republic and of Kazan, in comparison with the previous period, decreased significantly (by $26 \%$ in the municipalities of Kazan,by $20 \%$ in the region). In the structure of revenues there was a reduction level of grant revenue in the budget of the region and in the budget of Kazan.

Creating jobs is the basis of socio-economic development of the city and the region, with the positive effect of their creation is not only measured by wages. In the observed period, the preparations and holding of the Universiade 2013 was the main reason for the increase of this index in Kazan. The number of jobs increased by 823 (increase by $42 \%$ relative to 2009 ).

In the analyzed period, any appreciable increase in the number of new businesses not observed.

The total amount of wages paid by the Universiade activities increased by 1.2 times in the period $2009-2012$ during the the Universiade and after it fell.

Uniformly enough infrastructure for people with disabilities has evolved.

According to the results, for the period under review there was activation in sphere of housing construction. Its volumes during the the Universiade rose 1.41 times compared to 2009, the pace continued in the subsequent period.

During the period of time tends to increase the capacity of the sports facilities identified. During the period of its implementation growth was recorded almost in 2 times in comparison with the values of 2009-2011.

Universiade venues after its holding in demand for international, national and regional sporting events. They are used for sessions of mass sports, including for people with disabilities. However, the proportion of use of facilities for major national and international competitions has decreased several times, which is the objective trend.

Preparation and holding of the Universiade had a major positive impact on the development of transport infrastructure in Kazan. Analysis of the composite evaluation index shows improvement of parameters of its operation by $40-50 \%$. This was achieved mainly through the construction and reconstruction of $78.5 \mathrm{~km}$ of roads, completion of the new passenger terminal of the international airport "Kazan". Transport system of the Universiade led to an increase in passenger traffic and transport congestion highways during the Universiade. 


\section{Assessment of the Impact on Social Indicators}

Analysis of the dynamics of evaluation indicators of the social system of Kazan and Tatarstan showed conflicting trends (Table 2). A number of indicators, due to the absence of the component indicators were evaluated differently than it was defined during the development of evaluation methods, as their measurement in 2009 was not possible in principle. For a number of indicators the analysis was possible only for the period after 2013.

In general, the indicators of socio-cultural development of overall growth of indicators has been seen. This fact shows an overall positive influence of Universiade on the socio-cultural life of Kazan and the region as a whole.

Universiade 2013 brought together all segments of the population with different incomes and different interests. Involvement of society in the cultural life of the republic of Tatarstan in the period from 2009 to 2012 has increased. Stable from year to year increased the number of visits to museums and theaters, increased circulation of books and brochures. There was a significant increase in the number of people engaged in physical culture and sports in the whole republic as well as for the city of Kazan. Increased activity of organizations aimed at improving the social situation in the country.

Since 2010, the interest of young people in training in sport specialties began to grow. Cluster specializing in education in the sports field in the Volga Federal District gradually shown in Kazan. Established Volga State Academy of Physical Culture, Sports and Tourism is the largest institution of higher education of such profile.

Great importance is the development of the media to generate loyalty of the population (Cook, 1983). Assessing the implementation and use of new information and communication technologies in Tatarstan in the period from 2009 to 2012, it should be noted the progress made by the information society in the region in terms of introducing new standards of broadcast and broadband. In 2012, the first time in Russia digital television broadcasting in the format of DVB-T2 was launched on the basis of Kazan telecentre. In this format broadcasting in 8 rural areas of the republic started.

During the Universiade extensive cultural program was organized in parallel with sporting events. Opera and Ballet Festival, III International Festival "White Lilac", International Festival "Literary Universiade" were passed.

During carrying out the Kazan Universiade welcoming atmosphere reigned. This is evidenced by the results of the opinion polls conducted. Respondents noted the friendly environment, the festive atmosphere of the city. They also noted the convenience of the location of facilities and the Park of Universiade. Most pointed to the beauty and purity of the events in the city. In turn, a survey of businessmen of Kazan (the owners of cafes and souvenir shops) showed that in general the Universiade positively impact their activities, increased buying activity.

Was provided fairly high level of security. 30 days before the Universiade and at the time of its implementation there was a decrease in reported crimes. One of the factors in this positive changes in the situation is the encouragement of systematic work with young people in preparation for the Universiade, the involvement of young people in volunteer projects, creating motivation to maintaining a healthy lifestyle and a distraction from the effects of the crime situation.

In the period from 2009 to early 2014 quite rapidly press market has developed. Number of newspapers published in Tatarstan, has increased by $18.6 \%$. Conducted content analysis of media coverage suggests that the tone of printed material was mostly positive or neutral, and information rich.

Thus, the holding of Universiade-2013 was a notable incentive for activation of social activities in the city and the region, especially in the field of sport, physical education of the population, leading a healthy lifestyle.

\section{Environmental Impact Assessment}

Major international competitions often has negative consequences for the environment, which is observed in many countries around the world (Mingazova et al., 2013).

In general, integrated environmental studies during the organization and holding of the Universiade 2013 marked deterioration of a number of environmental indicators (Table 2) attesting incomplete accordance the results of the Universiade on the requirements of sustainable development. This kind of trend is due to the negative influence exerted on the ecosystem of the city and its historically preserved valuable natural areas in the course of construction of the Universiade. For a number of indicators any changes were not detected. A positive role of measures on preparation and holding of Universiade was expressed mainly in increasing the area and improvement of the green plantations in Kazan. Implementation of the municipal program "Green record" has 
allowed some neutralize of loss of green space, which occurred on the territory of Kazan from the beginning of the 2000s.

When considering the individual indicators it was revealed that quality of surface water has been subject to negative impacts from the construction of facilities of the Universiade on the banks of the Kazanka river and Lake Middle Kaban. Monitoring of the state the water bodies of the city (Mingazova, Derevenskaya, Barieva, \& Pavlova, 2009; Mingazova et al., 2011) showed a decrease in the ability of Kazanka river to cleanse itself and water quality deterioration by hydrobiological and hydrochemical parameters. Preparation and carrying out of the Universiade had no impact on the water quality of Kuibyshev reservoir and Kama river.

Analysis of air pollution showed that during the analyzed period this indicator has worsened (Table 2) due to the growth of road transport. Assessment of the dynamics of atmospheric emissions of gases that cause the greenhouse effect, has not revealed pronounced trend changes. The largest greenhouse gas emissions from motor vehicles registered in the area of the central objects (Central Stadium, the Universiade Village, Palace of Martial Arts "Ak Bars" stadium "Rubin"). The results of measurements of greenhouse gas emissions from motor vehicles after the Universiade showed no exceedances of the maximum single limit values for suspended solids, sulfur dioxide, nitrogen dioxide, methane, formaldehyde.

During the review period there has been some increase in the volume of wastewater undergoing cleaning sewerage system, compared with the initial 2009. At the same time carrying out preparations for the Universiade has not led to the construction of new facilities for cleaning waste water and sewage. During the construction of the Center for rowing sports on the shores of Lake Middle Kaban planned construction of sewage treatment plants was not implemented on the release of wastewater entering stormwater. Number of treatment plants and sewage waste in Kazan remained at the same level, which increased the burden on the existing structures and, consequently, the likelihood of accidents.

Preparation for the Universiade contributed to the rapid greening of the city and sports facilities. In the species composition of tree species used for landscaping sports facilities, young spruce trees, linden, heart and mountain ash prevailed. Shrub and flower forms distributed slightly. Vast space not occupied by trees and shrubs, were decorated by lawns.

Green spaces in the city is one of the key components of the environment carcass of territory (Mingazova, Yupina, Derevenskaya, \& Illarionova, 2008; Nikitin, Mingazova, \& Yupina, 2010). Assessment of the state of green space by results of direct field studies conducted in the location the Universiade venues and the surrounding areas greened, showed that the vital condition of the trees is estimated mainly 1 and 2 classes of quality it is highly decorative healthy and slightly weakened trees. Due to the late planting and desiccation later part of trees was planted again.

Preparation of the Universiade and its holding adversely impacted on Biological Diversity and the value of natural areas. Relatively rich biodiversity for urboterritory of Kazan (Mingazova et al., 2008) was subject to significant impacts in preparation for the Universiade 2013. On the Kazanka river during construction a football stadium and Water Sports Palace habitats of aquatic organisms, spawning fish were violated. There is a tendency reducing the number of species of vascular plants and vertebrates in all territorial clusters. Transformation of natural habitats has led to the loss of a significant part of the rare and endangered species of plants and animals.

While analyzing the effects of the Universiade a survey to identify the environmental impacts of the event was conducted among residents and guests of Kazan Universiade. The results showed that, overall, the opinion of the respondents indicating favorable attitude toward change occurred in the situation and do not correspond to the results of the environmental studies.

Social analysis revealed that during the Universiade-level international competitions activation occurs on winning in sports, and this leads to the fact that environmental issues are the subject of less concern (Zamaletdinov, Kornilov, Mingazova, \& Dautov, 2014). Thus, the formation of environmental attitudes and perceptions during the Universiade 2013 in Kazan acquired specific nature and characteristics.

\section{Conclusion}

The results of these studies demonstrated in overall mixed picture of the impact of the XXVII World Summer Universiade 2013 on the development of the city and the region, which corresponds to the known world trends for major international competitions.

XXVII World Summer Universiade 2013, held in of Kazan, has led to a fundamental transformation of the urban environment, changing the nature of the socio-economic development of the city, which influenced the development of the Republic of Tatarstan and Russia. These effects are ambiguous at different levels and 
subsystems, and have a complex and contradictory character. Occur as negative symptoms (worsening of several indicators of the state of the environment, and others.) but also positive (increasing the number of residents involved in sports, the growth of patriotism, etc.). The impact of the Universiade, especially in social and environmental terms, has long-term nature and in many cases will have a delayed effect, illustrating for 10-50 years or more.

Research results represent not only the scientific but also practical interest, allowing to optimize the work of organizing major international sporting events in the light of the implementation of the general concepts of sustainable development of the city and the region. They are particularly relevant to Kazan and Tatarstan in the light of their future in major international sporting events.

\section{References}

Cook, F. (1983). Media and agenda setting: effects on the public, interest group leaders, policy makers, and policy. In T. Tyler., G. Edward, M. Gordon, D. Protess, D. Leff, \& H. Molotch (Eds.), The public opinion quarterly (Vol. 47, No. 1).

Ely, A., Smith, A., Stirling, A., Leach, M., \& Scoones, I. (2013). Innovation politics post-Rio+20: Hybrid pathways to sustainability. Environment and Planning C: Government and Policy, 31(6), 1063-1081.

Malfas, M., Theodoraki, E., \& Houlihan, B. (2004). Impacts of the Olympic Games as mega-events. Proceedings of the Institution of Civil Engineers: Municipal Engineer, 3, 209-220.

Mingazova, N. M, Zamaletdinov, R. I., Safiulin, L. N., Gafurov, I. R., Bagautdinova, N. G., Panasiuc, M. V., \& Glebova, I. S. (2013). Organizational aspects of the study of influence of the XXVII World Summer Universiade 2013 in Kazan on the development and the region. International scientific-practical conference "Heritage major sporting events as a socio-cultural and economic development of the region": Proceedings (S. 19-21). Kazan.

Mingazova, N. M., Derevenskaya, O. Y., Nabeeva, E. G., Palagushkina, O. V., Unkovskaya, E. N., Ahatova, V.M., Pavlova, L. R., \& Barieva, F. F. (2011). The concept of biological rehabilitation of Lake Kaban in city Kazan on the base of condition monitoring. Ecological systems and devices, 3, 3-9.

Mingazova, N. M., Derevenskaya, O. Y., Palagushkina, O. V., Pavlova, L. R., Nabeeva, E. G., Zaripova, N. R., ... Khaliullina, L. Y. (2008). Biodiversity of water objects in Kazan sity. Scientific notes of Kazan University. Series of Natural Sciences, 150(4), 252-260.

Mingazova, N. M., Yupina, G. A., Derevenskaya, O. Yu., \& Illarionova, M. N. (2008). Ecology. Environment. Water bodies and green areas. Urban revitalization and redevelopment of Volga district territories in the city of Kazan (Center Waterfront Area of Volga River). International Urban design workshop. Background information, 24- 25. Kazan.

Mingazova, N., Derevenskaya, O., Barieva, F., \& Pavlova, L. (2009). Restoration of Low Kaban Lake (Kazan, Russia): 25-term experience of restoration and monitoring of ecological condition. In 13th World Lake Conference, Abstract Volume, 299-305. Wuhan-China, 2009.

Mudarisov, R. A., \& Mingazova, N. M. (2011). The methodological approaches to assessing the impact of economic activities on water bodies. Proceedings of the Kazan State Architectural University, 1(15), 65-71.

Nikitin, A. V., Mingazova, N. M., \& Yupina, G. A. (2010). Problems of formation of ecological-natural framework of urbanized areas (for example, the city of Kazan). Proceedings of the Kazan State Architectural University, 14, 88-96.

The concept of environmental protection in the preparation and conduct of the XXVII World Summer Universiade 2013 in Kazan with the action plan. (2010). FSI UralNII "Ecology", 123.

Zamaletdinov, R., Kornilov, P., Mingazova, N., \& Dautov, A. (2014). Transformation of Social and Environmental Views during the Sporting Events (on an Example of the Kazan Universiade 2013). Mediterranean Journal of Social Sciences, 235-239. MCSER Publishing, Rome-Italy.

\section{Copyrights}

Copyright for this article is retained by the author(s), with first publication rights granted to the journal.

This is an open-access article distributed under the terms and conditions of the Creative Commons Attribution license (http://creativecommons.org/licenses/by/3.0/). 